Editorial

\title{
Journalism and Social Media: Redistribution of Power?
}

\author{
Marcel Broersma * and Scott A. Eldridge II \\ Centre for Media and Journalism Studies, University of Groningen, Groningen, The Netherlands; \\ E-Mails: m.j.broersma@rug.nl (M.B.); s.a.eldridge.ii@rug.nl (S.A.E.) \\ * Corresponding author
}

Submitted: 1 March 2019 | Published: 21 March 2019

\begin{abstract}
This thematic issue sets out to explore the power relationships between journalism and social media. The articles here examine these relationships as intersections between journalistic actors and their audiences, and between news media, their content, and the functions of social media platforms. As the articles in this issue show, the emergence of social media and their adoption by news media and other social actors have brought about a series of changes which have had an impact on how news is produced, how information is shared, how audiences consume news, and how publics are formed. In this introduction, we highlight the work in this issue in order to reflect on the emergence of social media as one which has been accompanied by shifts in power in journalism and its ancillary fields, shifts which have in turn surfaced new questions for scholars to confront.
\end{abstract}

\section{Keywords}

journalism; news ecology; normalization; power; social media

Issue

This editorial is part of the issue "Journalism and Social Media: Redistribution of Power?", edited by Marcel Broersma and Scott A. Eldridge II (University of Groningen, The Netherlands).

(C) 2019 by the authors; licensee Cogitatio (Lisbon, Portugal). This article is licensed under a Creative Commons Attribution 4.0 International License (CC BY).

\section{Introduction}

Over the course of the last decade, social media and journalism have come to be featured more and more in the same academic conversations as scholars have sought to join up their understanding of a familiar communicative practice in journalism with new avenues for doing so found in social media. Studies have examined the ways social media platforms are used as sources for news (Broersma \& Graham, 2013; Hermida, 2010; Paulussen \& Harder, 2014), have been integrated into the dynamics of journalism practice (Beckers \& Harder, 2016; Bossio, 2017), and woven into processes of communicating information, including news, to publics (Bruns, 2018; Skogerb $\varnothing \&$ Krumsvik, 2015). Social media feature prominently in terms of how publics are made aware of news, both in public (Fletcher \& Kleis Nielsen, 2018) and in private (Swart, Peters, \& Broersma, 2018a, 2018b). As we put forward when announcing this issue, they have become so prevalent in conversations about journalism, social media are described as something 'normalized' and regularly fitted into the functions of journalism (Broersma \& Graham, 2015; Lasorsa, Lewis, \& Holton, 2012; Parmelee, 2013).

While we know, to some degree, this has occurred, the ways journalism and social media have intertwined have become more complex as actors at all levels-from the subjects of coverage, to journalists, to those consuming news-engage within these spaces. As much as we see social media as a largely normalized feature of news media, this normalization has not been entirely seamless. The dominant normalization framework and the prevalent focus in (digital) journalism studies on how the digital has been integrated into journalism (Eldridge, Hess, Tandoc, \& Westlund, in press), might obscure our understanding of how journalistic norms, practices, and forms are changing more fundamentally (cf. Broersma, 2019). We see in the articles here how journalists are 
increasingly engaging with the features of social media, including finding avenues on social media for reaching audiences. We also see a coming together of old power relationships and new ones, including those emerging with other agents in the networked ecology of news. These dynamics have been met with varying responsessometimes enthusiastic, other times cautious, yet each nevertheless showing these intersecting spaces can no longer be discussed separately.

In this issue we have articles working to understand journalism and social media, and from that work surface new questions for media scholars to consider as we continue to examine the possible reorientations of power $d y$ namics that have accompanied these developments. This includes the ways in which these shifts have moved from journalistic media towards social media, where new platforms have become 'normal' avenues for news to reach publics, and where these platforms have enabled movements away from journalism as a space for mediating between social actors and publics.

\section{Contextualizing Social Media, Journalism and Power}

While the term normalization makes salient how social media are commonplace in journalism, the textures of this coming together differ from other developments seen in the emergence of digital journalism (Eldridge, 2018; Eldridge \& Franklin, 2019). With social media, the opportunities to engage online have at times been embraced enthusiastically (Posetti, 2018), but they have also brought about a "lingering unease" as the logics of social media and the logics of journalism clash, as Axel Bruns and Christian Nuernbergk (2019) argue in their article here. Indeed, the adoption of social media were less quickly normalized than their digital predecessors, such as blogs and websites around the turn of the century (Singer, 2005). In Bruns and Nuernbergk's (2019) comparison of Australian and German political journalists' Twitter use, they nevertheless find that despite unease, this has become more widespread, and so too has "the gradual but inexorable influence of social media logics on professional journalism". Their article and Kelly Fincham's (2019) both engage with these findings within a discussion of homophily.

Describing a tendency towards sameness in terms of the people journalists interact with, Kelly Fincham (2019) finds political journalists on Twitter replicate the "insular groups" of small offline journalism communities, now found in "virtual journalism packs". Her article examines this in the interactions among US and UK political journalists in 2016 and 2017, when each country had a nationwide election (a US Presidential election in 2016, and a UK General Election in 2017). Fincham (2019) finds in these interactions a "sustained homophily as journalists continue to normalize Twitter". In contrast to Bruns and Nuernbergk's (2019) results, but complementing their argument, homophily is reflected differently within the cultures in which journalists are practicing, whether more pronounced as in the US and UK, or less so in Germany where the journalistic workforce, market structure, and cultures may have contributed to a slower adoption of new media opportunities. Thus, we see from these two studies that the ways in which social media and journalism intersect are not universally found, and the result of their emergence has not reflected one type of adoption, instead developing in many different forms.

Taking the way journalists engage on social media, and Twitter in particular, further, the article presented here by Chrysi Dagoula (2019), in line with discussions of homophily, finds a prevalence of in-group communication in a study on the nature of dialogue on Twitter. As a platform that, on paper, should engender openness, with the potential for a deliberative public sphere, discourse manifests quite differently in practice. On Twitter, Dagoula (2019) finds elite-centric discourses that fail to engage with a wider array of voices, pointing to more complex notions of exclusion and that any normative understanding of the public sphere must be evaluated based not only on the inclusivity of publics, but also of topics, and counter-publics and countertopics accordingly.

What these discussions bring to the foreground when considering complex power shifts between those being spoken about, the subjects of journalism, and those spoken to-the audiences of both social and news media. They draw our attention to a complex interplay between the logics of journalism, which tend towards certain traditional news practices, and emerging social media logics which push towards different objectives, such as engagement. Among the latter is what Monika Djerf-Pierre, Mia Lindgren, and Mikayla Alexis Budinski (2019) refer to as a "blind chase to maximize low-level engagement", where in an effort to maximize shares, clicks, and other markers of attention found on social platforms, news media first sought to produce content which can garner such reactions. In a mixed-method study, focusing on YouTube videos reporting on an antibiotic resistant 'Superbug', they also found that beyond this 'blind chase', their journalistic content on YouTube, journalists can be successful at building greater engagement, including "generating audience discussions about social and political accountability" when producing contextualized, journalistic, content. While accompanied by expressions of anger, and resentment, audiences nevertheless engage with the journalistic YouTube material and the way it is framed. This type of study, and its findings, open doors to new ways of considering engagement within these spaces, including new ways of qualitatively examining what type of content is engaged with by audiences that move beyond the technological markers of engagement-shares, likes, and similar.

Some of these findings highlight differences rooted in the nature of journalism prior to social media, and as Stephen Jukes (2019) writes in his article here, it is worth considering how journalists steeped in journalism's traditions and newsroom structures see Twitter as both an 
opportunity for self-promotion, and a platform that is incongruous with journalists' professional cultures, that "sits uneasily" with norms of detachment and distance. Jukes (2019) argues that, despite their reticence, journalists have nevertheless adopted the opportunity-and in doing so, crossed a previously distinct line between news work and the business of news. This is not something done unwittingly, or unaware of its implications. From interviews with journalists, Jukes finds that in response to the larger news industry crisis, and with an awareness of the opportunities which social media offer, these journalists are pragmatically engaging in these social opportunities.

Yet for news media, turning towards social media spaces for engagement can also result in a "dislocation" of news, shifting away from domains news media had more-or-less under their proprietary control on websites managed by news organizations, towards social media where this control is surrendered to large platform companies. As Oscar Westlund and Mats Ekström (2019) write, this has resulted in a "power redistribution from the news media to platform companies". This redistribution is in part a result of "dependencies", as news media rely on social media platforms for publishing their work and reaching audiences. Dislocation, however, also refers to a loss of power in terms of the ways the principles and contexts of news are presented, and not only a reallocation of content and revenue towards a new media space or company.

Such dislocation is also found, though quite differently, when attention is paid not to how social media have managed to secure control of news content and revenue, but in focusing on how other societal actors have been able to jump on social media platforms for their own ends in ways which may deprioritize journalism in the process. Scott Eldridge, Lucía García-Carretero, and Marcel Broersma (2019), consider politicians and political parties-traditionally the subject of media coverage, and not the makers of content-through Social Network Analysis to see how political actors construct publics in their own adoption of social media, finding this often elides journalistic actors and news media. This offers new ways of understanding publics in light of these dynamics, finding dynamics not of intersection, but of disintermediation as political actors bypass news media altogether in order to construct and speak to their own publics. While signaling new opportunities for political actors to reach their publics online, when it comes to understanding what this means for journalism and its relationship with its own publics, it raises key questions for their future.

\section{Conclusion: Looking Forward}

In the wake of a particularly tumultuous few years for news and journalism, where social media and their pervasive nature have been front and center and under public scrutiny, this thematic issue engages with this tumult as an opportunity to consider anew the relationships between journalism, social media, and the mechanisms of power. The articles assembled here reflect on the complex interrelationships between different societal actors in the public spaces where communication takes place on social media, and each highlights ways in which we can consider these within our discussions of journalism. They also show how, at the intersections of logics of news media and logics of social media, our understanding of audiences, publics, journalists, news media, and social media corporations have changed. This highlights where a more complex set of media dynamics has developed, and new challenges for scholars have emerged. Now the news ecology has become a hybrid space in which various actors engage with each other in different ways and as a consequence new power structures are established (cf. Chadwick, 2017), the articles in this issue offer us ways of understanding these.

Within these articles, there are also critical points of reflection for future work to pick up upon, offering guides for making sense of these power dynamics and relationships. These include findings which might give us pause by highlighting the scope and scale of change and the nature of the relationships between journalism and social media, and those which problematize the ways we might have understood the first decades of social media and journalism coming together. As Stephen Jukes (2019) writes in his article, when we talk about social media and journalism, our attention naturally turns towards making sense of the "sweeping changes wrought by social media". These changes continue to have an impact on the norms, practices, and forms of journalism, and continue to affect the ways in which we see news media working sometimes with and sometimes against social media. These changes, by extension, also signal a change in journalism's relationships with other agents in the networked ecology of news, including with sources, social media platforms, technology companies, and the citizens their content reaches. While journalism studies in the past decades has mainly focused on "how the digital has been integrated in journalism in terms of technologies, platforms, and businesses", a shift to studying "how journalism has been integrated into the digital" would be fruitful (Broersma, 2019, p. 516). The nature of the relationships between journalism and other actors in the networked ecology for news, and the power dynamics they draw upon, warrants further consideration by media scholars as we continue to try and understand the impact these have on society.

\section{Acknowledgments}

Our thanks extend to Cátia Simões and the team at Media and Communication for their support and assistance in bringing together this thematic issue, to the scholars who contributed to this issue, and to those who offered their guidance and feedback through the peer review and editorial processes. 


\section{Conflict of Interests}

The authors declare no conflict of interests.

\section{References}

Beckers, K., \& Harder, R. (2016). "Twitter just exploded": Social media as alternative vox pop. Digital Journalism, 4(7), 910-920.

Bossio, D. (2017). Journalism and social media: Practitioners, organisations and institutions. Basingstoke: Palgrave Macmillan.

Broersma, M. (2019). Situating journalism in the digital: A plea for studying news flows, users, and materiality. In S. Eldridge \& B. Franklin (Eds.), The Routledge handbook of developments in digital journalism studies (pp. 515-526). Abingdon: Routledge.

Broersma, M., \& Graham, T. (2013). Twitter as a news source: How Dutch and British newspapers used tweets in their news coverage, 2007-2011. Journalism Practice, 7(4), 446-464.

Broersma, M., \& Graham, T. (2015). Tipping the balance of power: Social media and the transformation of political journalism. In A. Bruns, E. Skogerb $\varnothing$, C. Christensen, A. O. Larsson, \& G. Enli (Eds.), The Routledge companion to social media and politics (pp. 89-103). Abingdon: Routledge.

Bruns, A. (2018). Gatewatching and news curation. London: Peter Lang.

Bruns, A., \& Nuernbergk, C. (2019). Political journalists and their social media audiences: New power relations. Media and Communication, 7(1), 198-212.

Chadwick, A. (2017). The hybrid media system (2nd ed.). Oxford: Oxford University Press.

Dagoula, C. (2019). Mapping political discussions on Twitter: Where the elites remain elites. Media and Communication, 7(1), 225-234.

Djerf-Pierre, M., Lindgren, M., \& Budinski, M. A. (2019) the role of journalism on YouTube: audience engagement with 'superbug' reporting. Media and Communication, 7(1), 235-247.

Ekström, M., \& Westlund, O. (2019). The dislocation of news journalism: A conceptual framework for the study of epistemologies of digital journalism. Media and Communication, 7(1), 259-270.

Eldridge, S. (2018). Repairing a fractured field: Dynamics of collaboration, normalization and appropriation at intersections of newswork. Journal of Applied Journalism \& Media Studies, 7(3), 541-599.

Eldridge, S., \& Franklin, B. (2019). Introducing the complexities of developments in digital journalism studies. In S. Eldridge \& B. Franklin (Eds.), The Routledge handbook of developments in digital journalism stud- ies (pp. 1-12). Abingdon: Routledge.

Eldridge, S., García-Carretero, L., \& Broersma, M. (2019). Disintermediation in social networks: Conceptualizing political actors' construction of publics on Twitter. Media and Communication, 7(1), 271-285.

Eldridge, S., Hess, K., Tandoc, E., \& Westlund, O. (in press). Navigating the scholarly terrain: Introducing the digital journalism compass. Digital Journalism.

Fincham, K. (2019). Exploring political journalism homophily on Twitter: A comparative analysis of US and UK elections in 2016 and 2017. Media and Communication, 7(1), 213-224.

Fletcher, R., \& Kleis Nielsen, R. (2018). Generalised scepticism: How people navigate news on social media. Information, Communication \& Society. https://doi.org/10.1080/1369118X.2018.1450887

Hermida, A. (2010). Twittering the news: The emergence of ambient journalism. Journalism Practice, 4(3), 297-308.

Jukes, S. (2019). Crossing the line between news and the business of news: Exploring journalists' use of Twitter. Media and Communication, 7(1), 248-258.

Lasorsa, D., Lewis, S. C., \& Holton, A. (2012). Normalizing Twitter: Journalism practice in an emerging communication space. Journalism Studies, 13(1), 19-36.

Parmelee, J. (2013). Political journalists and Twitter: Influences on norms and practices. Journal of Media Practice, 14(4), 291-305.

Paulussen, S., \& Harder, R. (2014). Social media references in newspapers. Journalism Practice, 8(5), 542-551.

Posetti, J. (2018). Time to step away from the 'bright, shiny things'? Towards a sustainable model of journalism innovation in an era of perpetual change. Oxford: University of Oxford.

Singer, J. (2005). The political j-blogger: "Normalizing" a new media form to fit old norms and practices. Journalism, 6(2), 173-198.

Skogerbø, E., \& Krumsvik, A. (2015). Newspapers, Facebook and Twitter: Intermedial agenda setting in local election campaigns. Journalism Practice, 9(3), 350-366.

Swart, J., Peters, C., \& Broersma, M. (2018a) Shedding light on the dark social: The connective role of news and journalism in social media communities. New Media \& Society, 20(11), 4329-4345.

Swart, J., Peters, C., \& Broersma, M. (2018b) Sharing and discussing news in private social media groups: The social function of news and current affairs in locationbased, work-oriented and leisure-focused communities. Digital Journalism. https://doi.org/10.1080/ 21670811.2018.1465351 


\section{About the Authors}

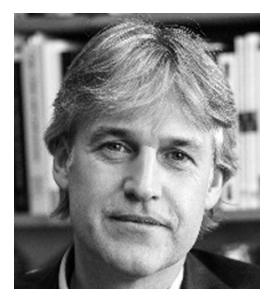

Marcel Broersma is Professor and Director of the Centre for Media and Journalism Studies at the University of Groningen. His research focuses on the current and historical transformation of journalism, and how journalists, politicians and citizens use social media in particular. He has published numerous articles in peer-reviewed journals, chapters, monographs, edited volumes and special journal issues on social media, transformations in journalism, journalism history and political communication. Among his recent publications are: Rethinking Journalism Again. Societal Role and Relevance in a Digital Age (2017; edited with Chris Peters) and Redefining Journalism in the Era of the Mass Press, 1880-1920 (2016; co-edited with John Steel). He chairs the boards of the Dutch Research School for Media Studies (RMeS) and of eHumanities.nl.

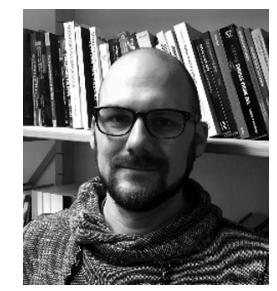

Scott A. Eldridge II is an Assistant Professor with the Centre for Media and Journalism Studies at the University of Groningen. He researches digital journalism and journalistic boundaries. He is the author of Online Journalism from the Periphery: Interloper Media and the Journalistic Field (2018) and co-editor with Bob Franklin of the Routledge Companion to Digital Journalism Studies (2017) and Routledge Handbook of Developments in Digital Journalism Studies (2019). He is an Associate Editor and Reviews Editor for the journal Digital Journalism. 